\title{
Notes From the Field: Use of Emergency Medical Service Data to Augment COVID-19 Public Health Surveillance in Montgomery County, Maryland, From March to June 2020
}

David R Sayers ${ }^{1}$, MD, MTM\&H; Scott T Hulse ${ }^{1}$, MD, MS, MPH; Bryant J Webber ${ }^{1}$, MD, MPH; Timothy A Burns ${ }^{2}$, MS, NRP; Anne L Denicoff ${ }^{3}$, RN, MSN, PNP

\footnotetext{
${ }^{1}$ Uniformed Services University of the Health Sciences, Bethesda, MD, United States

${ }^{2}$ Montgomery County Fire and Rescue Service, Gaithersburg, MD, United States

${ }^{3}$ Montgomery County Public Health Emergency Preparedness and Response Program, Rockville, MD, United States
}

\section{Corresponding Author:}

David R Sayers, MD, MTM\&H

Uniformed Services University of the Health Sciences

4301 Jones Bridge Rd

Bethesda, MD, 20814

United States

Phone: 12704038911

Email: david.sayers@usuhs.edu

\begin{abstract}
Epidemiologic and syndromic surveillance metrics traditionally used by public health departments can be enhanced to better predict hospitalization for coronavirus disease (COVID-19). In Montgomery County, Maryland, measurements of oxygen saturation $\left(\mathrm{SpO}_{2}\right)$ by pulse oximetry obtained by the emergency medical service (EMS) were added to these traditional metrics to enhance the public health picture for decision makers. During a 78-day period, the rolling 7-day average of the percentage of EMS patients with $\mathrm{SpO}_{2}<94 \%$ had a stronger correlation with next-day hospital bed occupancy (Spearman $\rho=0.58,95 \%$ CI $0.40-0.71$ ) than either the rolling 7-day average of the percentage of positive tests $(\rho=0.55,95 \%$ CI: $0.37-0.69)$ or the rolling 7-day average of the percentage of emergency department visits for COVID-19-like illness ( $\rho=0.49,95 \%$ CI: 0.30-0.64). Health departments should consider adding EMS data to augment COVID-19 surveillance and thus improve resource allocation.
\end{abstract}

(JMIR Public Health Surveill 2020;6(3):e22331) doi: 10.2196/22331

\section{KEYWORDS}

SARS-CoV-2; COVID-19; public health; surveillance; prediction; emergency medical service; EMS; pulse oximetry; testing

\section{Introduction}

On March 5, 2020, Montgomery County, Maryland, a densely populated county neighboring Washington, DC, reported its first cases of coronavirus disease (COVID-19); this prompted the county health department to develop a daily surveillance report [1]. By March 27, this report included the following information: daily and cumulative confirmed COVID-19 cases; percentage of reverse transcription polymerase chain reaction (RT-PCR) tests positive for severe acute respiratory syndrome coronavirus 2 (SARS-CoV-2), the virus that causes COVID-19; acute and intensive care unit beds occupied in the county's seven hospitals; daily emergency department encounters for COVID-19-like illness; and daily emergency medical service (EMS) calls and acuity indicators, including the number of patients with a pre-hospital pulse oximetry value $\left(\mathrm{SpO}_{2}\right)$ below
94\% [2]. Epidemiologic data were retrieved from the Maryland Department of Health. Emergency department syndromic data were retrieved from the Montgomery County Electronic Surveillance System for the Early Notification of Community-based Epidemics (ESSENCE) using the COVID-19-like illness query published by the National Syndrome Surveillance Program; this query is defined as fever plus cough, difficulty breathing, or shortness of breath, and it includes International Statistical Classification of Diseases, Tenth Revision (ICD-10) codes for COVID-19 [3]. EMS data were provided by the Montgomery County Fire and Rescue Service.

As the situation unfolded, it was noted that the percentage of EMS patients with $\mathrm{SpO}_{2}<94 \%$ tracked closely with the number of hospital beds occupied by patients with COVID-19 in the 
county (Figure 1). It was postulated that this metric, in addition to typical epidemiologic and syndromic surveillance data, may

be beneficial for hospital utilization forecasting.

Figure 1. Metrics associated with hospital bed occupancy for COVID-19 in Montgomery County, Maryland, from April 3 to June 20, 2020.

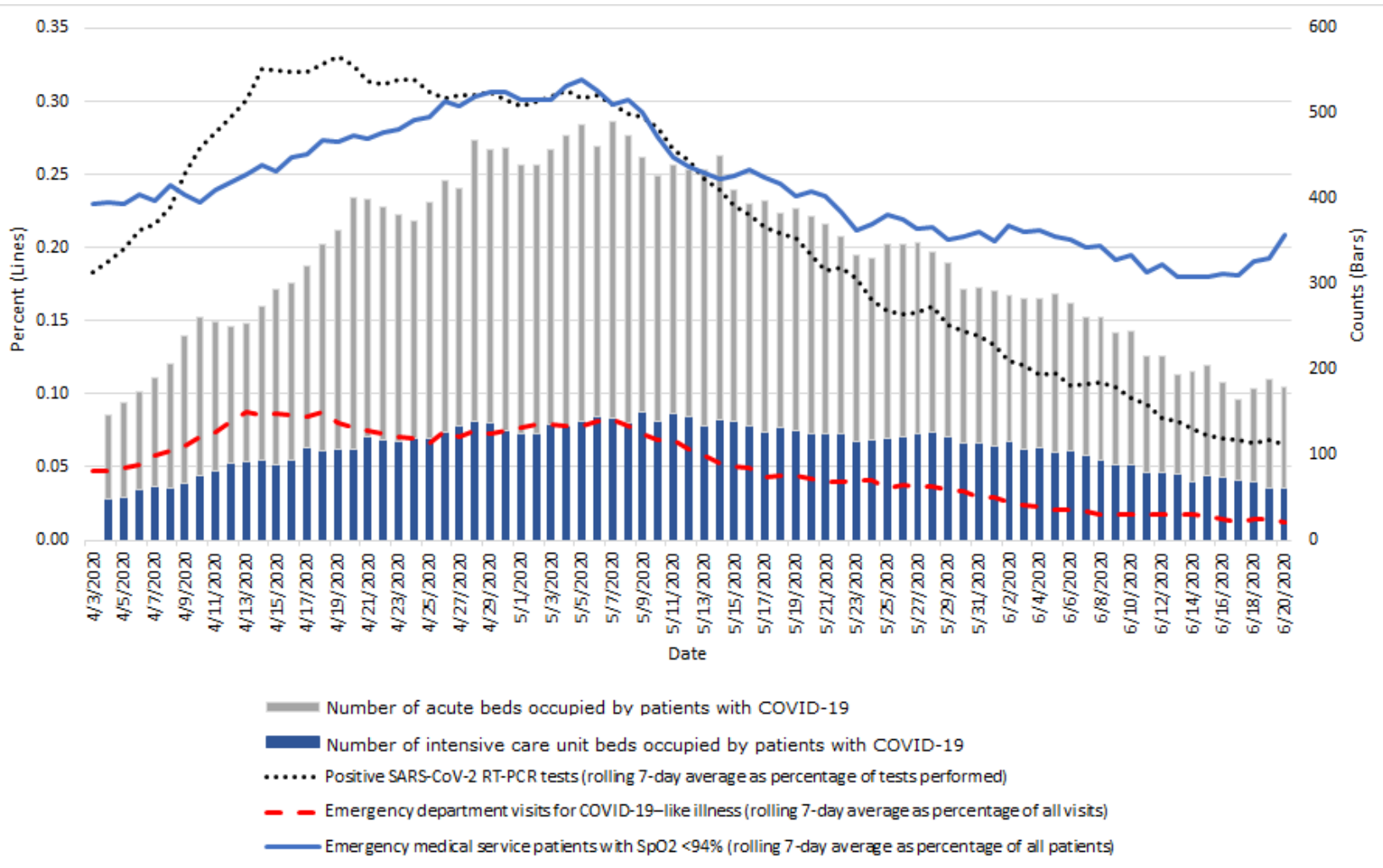

\section{Methods}

The relationship between prehospital hypoxemia and next-day hospital bed occupancy for COVID-19 was assessed using the Spearman rank-order correlation. Prehospital hypoxemia was defined as the rolling 7-day average of the percentage of EMS patients with $\mathrm{SpO}_{2}<94 \%$. The Spearman rank-order correlation was also used to assess the correlation between the rolling 7-day average of the percentage of RT-PCR tests that were positive for SARS-CoV-2 and next-day hospital bed occupancy, as well as the correlation between the rolling 7-day average of the percentage of emergency department visits for COVID-19-like illness and next-day hospital bed occupancy. Correlations were computed using SAS 9.4 (SAS Institute) with 95\% CIs based on the Fisher $\mathrm{z}$ transformation. This study was approved as exempt research by the Maryland Department of Health Institutional Review Board (protocol \#20-32).

\section{Results}

During the 78-day period from April 3 to June 19, 2020, the correlation coefficient $(\rho)$ between the rolling 7-day average of the percentage of EMS patients with $\mathrm{SpO}_{2}<94 \%$ and the total hospital bed occupancy on the following day (ie, from April 4 to June 20) was 0.58 (95\% CI 0.40-0.71). This correlation was stronger than those for the two other metrics commonly used to assess COVID-19 trajectory in a community: the rolling 7-day average of the percentage of positive tests $(\rho=0.55,95 \% \mathrm{CI}$ 0.37-0.69) and the rolling 7-day average of the percentage of emergency department visits for COVID-19-like illness $(\rho=0.49,95 \%$ CI $0.30-0.64)$.

\section{Discussion}

To reduce morbidity and mortality associated with the ongoing pandemic, government authorities and health care administrators must anticipate demands for hospital beds, equipment, and treatments [4]. These leaders will continue to rely on public health metrics to anticipate surges in the number of patients with COVID-19. The value of these metrics increases with their predictive ability and their nearness to real time [3,5]; ideally, extant metrics can be adopted without implementing novel data collection infrastructure [6].

Prehospital pulse oximetry may meet these requirements and surpass traditional surveillance measures for predicting COVID-19 hospitalizations for at least four reasons. First, by requiring two sets of vital signs and by documenting $\mathrm{SpO}_{2}$ for nearly every patient encounter regardless of presentation or working diagnosis, EMS has established a metric that is comprehensively ascertained and internally valid. Second, these data are usually generated before those from traditional health care sources, such as emergency department assessments and RT-PCR test results. Third, because hypoxemic patients are more likely than asymptomatic or mildly symptomatic patients to be hospitalized, the predictive criterion validity of $\mathrm{SpO}_{2}$ may surpass that of RT-PCR test positivity [7]. Fourth, although syndromic surveillance provides some information on disease severity, patient acuity indicators are not consistently populated in the Montgomery County syndromic system, and emergency 
department pulse oximetry measurements may be affected by oxygen administration in the prehospital environment.

In Montgomery County, Maryland, the 7-day rolling average of the percentage of EMS patients with $\mathrm{SpO}_{2}<94 \%$ correlated well with next-day hospitalizations for COVID-19. State and county health departments should consider tracking the hypoxemia status of prehospital patients by using EMS data to augment surveillance and improve their COVID-19 response.

\section{Acknowledgments}

The views expressed in this article are those of the authors and do not necessarily reflect the official policy or position of the Air Force, the Department of Defense, or the US Government.

\section{Conflicts of Interest}

None declared.

\section{References}

1. The Office of Governor Larry Hogan. Governor Larry Hogan Declares State of Emergency, Expands Statewide Response to Novel Coronavirus. Maryland.gov. 2020 Mar 06. URL: https://governor.maryland.gov/2020/03/05/ governor-larry-hogan-declares-state-of-emergency-expands-statewide-response-to-novel-coronavirus/ [accessed 2020-07-17]

2. COVID-19 Information Portal. Montgomery County Government. URL: https://montgomerycountymd.gov/covid19/data/ [accessed 2020-07-13]

3. COVIDView: A weekly surveillance summary of US COVId-19 activity. US Centers for Disease Control and Prevention. Atlanta, GA URL: https://www.cdc.gov/coronavirus/2019-ncov/covid-data/covidview/past-reports/04172020.html [accessed 2020-07-17]

4. Wilder-Smith A, Chiew CJ, Lee VJ. Can we contain the COVID-19 outbreak with the same measures as for SARS? Lancet Infect Dis 2020 May;20(5):e102-e107 [FREE Full text] [doi: 10.1016/S1473-3099(20)30129-8] [Medline: 32145768 ]

5. Wiemken TL, Shacham E. Identifying potential undocumented COVID-19 using publicly reported influenza-like-illness and laboratory-confirmed influenza disease in the United States: An approach to syndromic surveillance? Am J Infect Control 2020 May 11:1-3 [FREE Full text] [doi: 10.1016/j.ajic.2020.05.007] [Medline: $\underline{32437754]}$

6. Xu S, Li Y. Beware of the second wave of COVID-19. Lancet 2020 Apr 25;395(10233):1321-1322 [FREE Full text] [doi: 10.1016/S0140-6736(20)30845-X] [Medline: $\underline{\text { 32277876] }}$

7. Petrilli CM, Jones SA, Yang J, Rajagopalan H, O'Donnell L, Chernyak Y, et al. Factors associated with hospital admission and critical illness among 5279 people with coronavirus disease 2019 in New York City: prospective cohort study. BMJ 2020 May 22;369:m1966 [FREE Full text] [doi: 10.1136/bmj.m1966] [Medline: $\underline{\text { 32444366] }}$

\section{Abbreviations}

COVID-19: coronavirus disease

EMS: emergency medical service

ESSENCE: Electronic Surveillance System for the Early Notification of Community-based Epidemics

ICD-10: International Statistical Classification of Diseases, Tenth Revision

RT-PCR: reverse transcription-polymerase chain reaction

SARS-CoV-2: severe acute respiratory syndrome coronavirus 2

Edited by T Sanchez; submitted 08.07.20; peer-reviewed by S Doan, P Banik; comments to author 13.07.20; revised version received
14.07.20; accepted 15.07.20; published 31.07.20
Please cite as:
Sayers DR, Hulse ST, Webber BJ, Burns TA, Denicoff AL
Notes From the Field: Use of Emergency Medical Service Data to Augment COVID-19 Public Health Surveillance in Montgomery
County, Maryland, From March to June 2020
JMIR Public Health Surveill $2020 ; 6(3): e 22331$
URL: $\underline{\text { http://publichealth.jmir.org/2020/3/e22331/ }}$
doi: $10.2196 / 22331$
PMID: $\underline{32678799}$

CDavid R Sayers, Scott T Hulse, Bryant J Webber, Timothy A Burns, Anne L Denicoff. Originally published in JMIR Public Health and Surveillance (http://publichealth.jmir.org), 31.07.2020. This is an open-access article distributed under the terms of 
the Creative Commons Attribution License (https://creativecommons.org/licenses/by/4.0/), which permits unrestricted use, distribution, and reproduction in any medium, provided the original work, first published in JMIR Public Health and Surveillance, is properly cited. The complete bibliographic information, a link to the original publication on http://publichealth.jmir.org, as well as this copyright and license information must be included. 